DEVELOPMENT OF GATORIZED ${ }^{\circledR}$ MERL 76

FOR GAS TURBINE DISK APPLICATIONS

R. H. Caless and D. F. Paulonis

Materials Engineering

Pratt \& Whitney

400 Main Street

East Hartford, CT 06108

\begin{abstract}
The MERL 76 alloy was developed to produce components by hot isostatic pressing. To provide for enhanced shaping capability, improved material utilization, and to explore potential property benefits, Pratt \& Whitney embarked on a development program to qualify Gatorized ${ }^{\circledR}$ MERL 76 . The MERL 76 composition was fixed, and billets were consolidated by hot isostatic pressing (HIP), followed by Gatorizing ${ }^{\circledR}$ into the required component shape. Detailed studies were conducted to define both metal processing (e.g., HIP and forging) and heat treatment parameters. Comprehensive monotonic and fatigue testing of full-size components has demonstrated that Gatorized ${ }^{\circledR}$ MERL 76 met all program goals. This material has been used in commercial service since 1983, with excellent experience.
\end{abstract}


The demand for higher performance aircraft gas turbine engines with longer operating lives and improved reliability is the driving force for the development of new material and processing techniques. Higher performance can frequently be achieved by operating gas turbine components under conditions which result in higher stresses and higher temperatures. To meet the need for a higher strength alloy with intermediate temperature capability (up to $1350^{\circ} \mathrm{F}$ ) for use in disks, sideplates, etc., MERL 76 was developed in the mid-1970's for production of components by hot isostatic pressing (HIP). Alloy composition is shown in Table I. The direct HIP processing route was viewed as a method for manufacturing components very close to net shape for maximum material utilization and lowest cost $(1,2)$.

Table I. MERL 76 Composition (Weight Percent)

\begin{tabular}{llllllllllll}
\hline Element & $\mathrm{Ni}$ & $\mathrm{Cr}$ & $\mathrm{Co}$ & $\mathrm{Mo}$ & $\mathrm{Ti}$ & $\mathrm{A} 1$ & $\mathrm{Hf}$ & $\mathrm{Cb}$ & $\mathrm{B}$ & $\mathrm{Zr}$ & $\mathrm{C}$ \\
\hline Max & Balance & 12.9 & 19.0 & 3.6 & 4.50 & 5.15 & 0.9 & 1.6 & 0.024 & 0.08 & 0.035 \\
Min & Balance & 11.9 & 18.0 & 2.8 & 4.15 & 4.80 & 0.6 & 1.2 & 0.016 & 0.04 & 0.015 \\
\hline
\end{tabular}

Intensive studies during the late 1970's demonstrated that for many larger components, typical of those required for commercial engines, the promise of near net shape manufacture by HIP was never realized (3). It became evident that for such components, Gatorizing ${ }^{\circledR}$ to achieve part shape provided greater net shape capability and improved material utilization. Furthermore, initial exploratory studies by Pratt \& Whitney indicated potential property benefits for Gatorized ${ }^{\circledR}$ material. Therefore, a development program was initiated to qualify Gatorized ${ }^{\circledR}$ MERL 76 . The basic approach was to utilize the existing MERL 76 composition, produce billet by HIP, and then Gatorize (by isothermal forging) into component shapes. This paper traces the development of the process parameters for this product form and presents representative microstructures and mechanical property results generated during the development program.

\section{Subscale Process Development}

During the course of this program, forgings ranging in size from small 6-inch diameter subscale disks to full-size engine turbine disks were evaluated. To minimize the size of life limiting inclusions, -325 mesh powder, the same as used in the direct HIP product form, was selected as a product requirement. The forgings described in this paper were produced by several qualified production suppliers.

In the initial stages of this effort, HIP and forge process parameters were evaluated, and selections were made based on forgeability and resultant mechanical properties. In the evaluation of HIP parameters, time and pressure were kept constant at 3 hours and $15 \mathrm{ksi}$, respectively. These parameters represent common industry practice and also work effectively for direct HIP MERL 76. Temperature was the only variable. Small billets were hot isostatically pressed at 2050,2100 , and $2150^{\circ} \mathrm{F}$ (a11 subsolvus - the gamma prime solvus of MERL 76 is approximately $2170^{\circ} \mathrm{F}$ ). Grain sizes of these billets increased slightly (from ASTM 10.8 to ASTM 10.2) as the HIP temperture increased; there were no major differences in gamma prime morphology as a function of HIP temperature, although the $2150^{\circ} \mathrm{F}$ HIP exposure did result in slightly coarsened primary gamma prime. Photomicrographs of this material are shown in Figure 1 . 


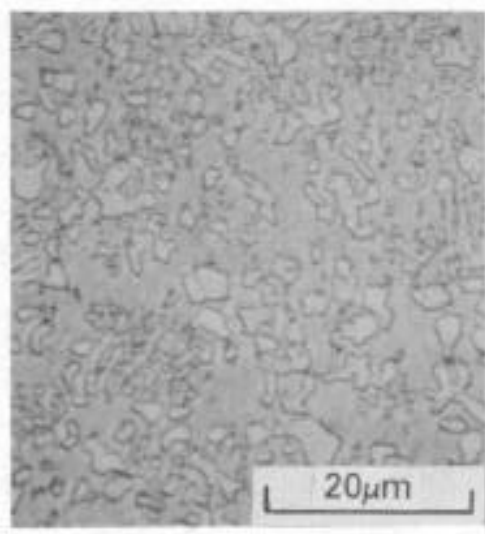

(a) $2050^{\circ} \mathrm{F}$ HIP

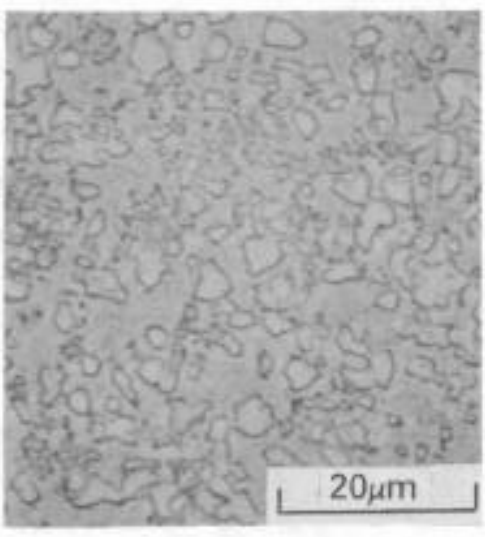

(b) $2100^{\circ} \mathrm{F} \mathrm{HIP}$

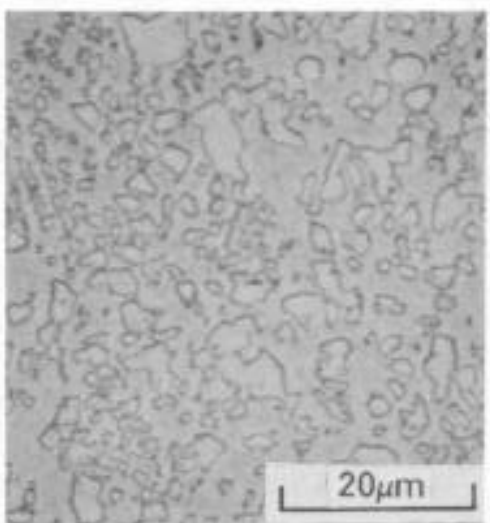

(c) $2150^{\circ} \mathrm{F}$ HIP

Figure 1 - Microstructure of MERL 76 processed at various HIP temperatures. Slight coarsening of gamma prime is evident for the $2150^{\circ} \mathrm{F}$ HIP condition.

These billets were then Gatorized ${ }^{\circledR}$ at $2050^{\circ} \mathrm{F}$ and a strain rate of 0.1 in/in/minute into 6-inch diameter subscale disk shapes (Figure 2). Forging proceeded smoothly with no evidence of cracking. The forge flow stresses (shown in Table II) increased from 6.6 to $12.0 \mathrm{ksi}$ for the three HIP temperatures. Tensile testing of these subscale parts did not reveal any significant difference in mechanical properties among the three HIP temperatures. The tensile properties are listed in Table III. A HIP temperature in the middle of the range studied $\left(2100^{\circ} \mathrm{F}\right)$ was selected based on the relative insensitivity of processing and property results to this temperature (thereby providing a wide tolerance band).

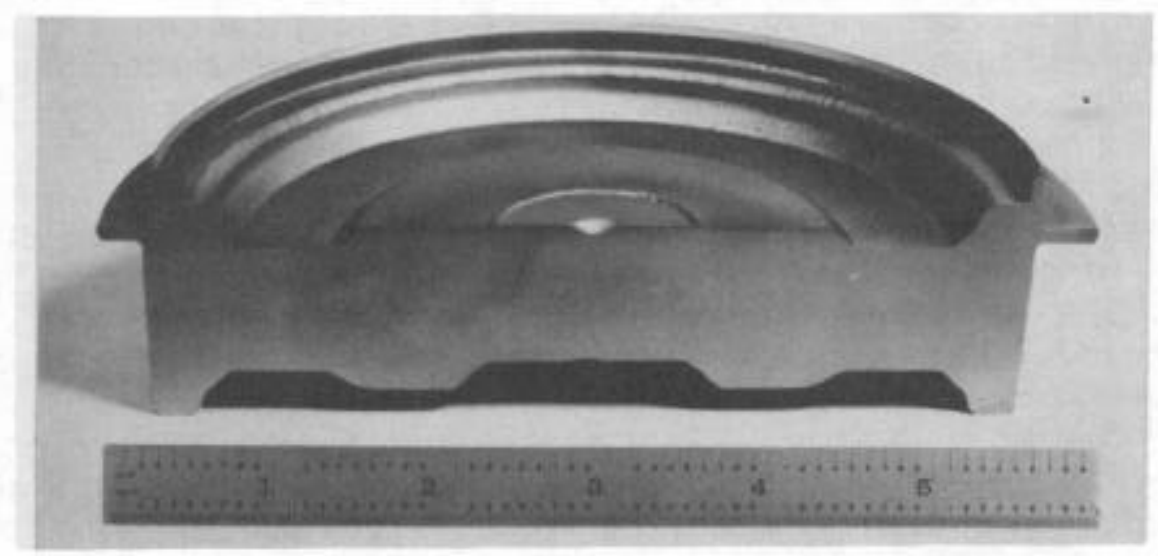

Figure 2 - Subscale Gatorized® MERL 76 disk.

Table II. Grain Size and Flow Stress of MERL 76 Versus HIP Temperature

\begin{tabular}{ccc} 
HIP Temperature $\left({ }^{\circ} \mathrm{F}\right)$ & Grain Size (ASTM) & Flow Stress (ksi) \\
\hline 2050 & 10.2 & 6.6 \\
2100 & 10.5 & 9.5 \\
2150 & 10.8 & 12.0 \\
\hline
\end{tabular}


Table III. Tensile Properties Versus HIP Temperature of Gatorized ${ }^{\circledR}$ MERL 76 Subscale Forgings Solution Heat Treated at $2075^{\circ} \mathrm{F}$

\begin{tabular}{|c|c|c|c|c|c|c|c|c|}
\hline \multirow[b]{2}{*}{$\begin{array}{c}\text { HIP Temp. } \\
\left({ }^{\circ} \mathrm{F}\right)\end{array}$} & \multicolumn{4}{|c|}{ Room Temperature } & \multicolumn{4}{|c|}{$1150^{\circ} \mathrm{F}$} \\
\hline & $\begin{array}{c}0.2 \% \text { YS } \\
\text { (ksi) }\end{array}$ & $\begin{array}{l}\text { UTS } \\
\text { (ksi) }\end{array}$ & $\% \mathrm{EL}$ & $\%$ RA & $\begin{array}{c}0.2 \% \text { YS } \\
\text { (ksi) }\end{array}$ & $\begin{array}{l}\text { UTS } \\
\text { (ksi) }\end{array}$ & $\% E L$ & $\%$ RA \\
\hline 2050 & 150 & 227 & 31 & 34 & $\begin{array}{l}146 \\
143\end{array}$ & $\begin{array}{l}198 \\
196\end{array}$ & $\begin{array}{l}31 \\
31\end{array}$ & $\begin{array}{l}33 \\
33\end{array}$ \\
\hline 2100 & 149 & 227 & 29 & 32 & $\begin{array}{l}147 \\
144\end{array}$ & $\begin{array}{l}199 \\
200\end{array}$ & $\begin{array}{l}31 \\
33\end{array}$ & $\begin{array}{l}35 \\
35\end{array}$ \\
\hline 2150 & 147 & 226 & 25 & 30 & $\begin{array}{l}150 \\
149\end{array}$ & $\begin{array}{l}200 \\
199\end{array}$ & $\begin{array}{l}31 \\
36\end{array}$ & $\begin{array}{l}33 \\
36\end{array}$ \\
\hline
\end{tabular}

Having selected the HIP conditions, the next requirement was to select isothermal forging parameters. These were selected separately by each supplier based on trials conducted by the suppliers. The parameters selected were in the range of normal production practice: strain rate $=0.05$ to 0.2 in/in/minute, and temperature 2050 to $2100^{\circ} \mathrm{F}$. The mechanical properties were not affected over the range of parameters studied.

Significant development effort concentrated on the identification of a heat treatment cycle. For reference, the standard heat treatment for direct HIP MERL 76 (2) is:

$\begin{array}{lll}0 & \text { Solution: } & 2125^{\circ} \mathrm{F} / 2 \text { hours } / 0 \mathrm{Q} \\ 0 & \text { Stabilize: } & 1600^{\circ} \mathrm{F} / 40 \text { minutes } / A C+1800^{\circ} \mathrm{F} / 45 \text { minutes } / \mathrm{AC} \\ 0 & \text { Age: } & 1200^{\circ} \mathrm{F} / 24 \text { hours } / \mathrm{AC}+1400^{\circ} \mathrm{F} / 16 \text { hours } / \mathrm{AC} .\end{array}$

The solution cycle is conducted at a temperature below the gamma prime solvus and incorporates a rapid oil quench to solution most of the gamma prime. However, enough gamma prime is retained at temperature to pin grain boundaries and maintain a fine grain size.

The stabilize cycle is conducted at a sufficiently high temperature to relieve stresses created as a result of the prior oil quench and also to provide a uniform dispersion of intermediate size gamma prime.

The aging cycle creates a dispersion of very fine "aging" gamma prime which provides further increases in tensile strength.

Experience on the direct HIP product form demonstrated that these three heat treatment steps and an oil quench $(0 Q)$ from the solution temperature were necessary and would be retained; however, some refinement and simplification of the specific temperature/time parameters appeared desirable. The objective was to identify a sequence which: (1) was simple and low-cost, (2) minimized residual stress, and (3) resulted in the best balance of mechanical properties.

Separate studies were conducted for each step in the heat treat sequence. Most of this work was conducted on pancake forgings (produced by Wyman-Gordon) which were either 2 or 4 inches thick and weighed from 175 to 225 pounds. In addition, several 125-pound closed die disk-shaped forgings (produced and tested by Ladish Co.), which were 14-inch diameter $x$ 4-inch thick, were used to evaluate alternative stabilize cycles. 
The standard solution temperature for direct HIP MERL 76 is $2125^{\circ} \mathrm{F}$. In this study, temperatures ranging from 2065 to $2125^{\circ} \mathrm{F}$ were examined. A 2-hour hold and oil quench (to maximize strength) were fixed at the outset, along with a standard $1200^{\circ} \mathrm{F} / 24$ hour $+1400^{\circ} \mathrm{F} / 16$ hour age. As shown in Table IV, solution temperatures in the higher part of the range produced a slight advantage. These results, coupled with some concern for quench cracking from the highest temperature $\left(2125^{\circ} \mathrm{F}\right)$, resulted in selection of a $2090^{\circ} \mathrm{F}$ solution temperature.

Table IV. Tensile Properties of Gatorized ${ }^{\circledR}$ MERL 76 at Various Solution Temperatures

\begin{tabular}{|c|c|c|c|c|c|c|c|c|}
\hline \multirow[b]{2}{*}{$\begin{array}{c}\text { Solution Temp. } \\
\left({ }^{\circ} \mathrm{F}\right)\end{array}$} & \multicolumn{4}{|c|}{ Room Temperature } & \multicolumn{4}{|c|}{$1150^{\circ} \mathrm{F}$} \\
\hline & $\begin{array}{l}\overline{Y S} \\
(k s i)\end{array}$ & $\begin{array}{l}\text { UTS } \\
\text { (ksi) }\end{array}$ & $\% E L$ & $\%$ RA & $\begin{array}{c}\overline{Y S} \\
(\mathrm{ksi})\end{array}$ & $\begin{array}{c}\text { UTS } \\
\text { (ksi) }\end{array}$ & $\%$ EL & $\%$ RA \\
\hline $\begin{array}{l}2065 \\
2100 \\
2125\end{array}$ & $\begin{array}{l}163 \\
158 \\
165\end{array}$ & $\begin{array}{l}236 \\
236 \\
241\end{array}$ & $\begin{array}{l}23 \\
25 \\
24\end{array}$ & $\begin{array}{l}25 \\
27 \\
25\end{array}$ & $\begin{array}{l}151 \\
150 \\
153\end{array}$ & $\begin{array}{l}206 \\
205 \\
208\end{array}$ & $\begin{array}{l}27 \\
27 \\
27\end{array}$ & $\begin{array}{l}28 \\
31 \\
33\end{array}$ \\
\hline
\end{tabular}

Since a component in the solution and oil quenched condition contains very high residual stresses, adequate stress relief was considered a major criterion for a stabilize cycle. Two additional criteria were: (1) attainment of satisfactory mechanical properties, and (2) avoidance of embrittling grain boundary phases which can occur in this class of alloys at intermediate $\left(1500\right.$ to $\left.1700^{\circ} \mathrm{F}\right)$ temperatures. Temperatures in the range of 1400 to $1800^{\circ} \mathrm{F}$ were evaluated.

Initially, stress relief effects were evaluated by oil quenching a number of available direct HIP MERL 76 cylinders (8-inch diameter $x$ 2-inch thick) from $2090^{\circ} \mathrm{F}$, exposing each to a different stabilize heat treat cycle and then measuring the contraction which occurred on cutting the cylinder. An assessment of the effectiveness of stress relief was made by comparing these figures to the contraction measured on an as-quenched sample. Representative results from this study, as plotted in Figure 3, indicate that acceptable levels of stress relief can be accomplished at $1550^{\circ} \mathrm{F}$ and above. Limited property evaluation of selected conditions revealed a drop in room temperature (RT) ductility after 1550 or $1600^{\circ} \mathrm{F}$ exposure. Detailed metallographic, extraction replica, and energy dispersive spectroscopy (EDS) analyses (Figure 4) of samples with high and low ductility revealed the likely source of the property debit to be a semi-continuous film of sigma precipitation at grain boundaries in this intermediate temperature regime. Subsequent work has shown that by careful control of alloy chemistry, these microstructural effects (and associated property debits) can be minimized.

Similar property trends were observed on a series of closed die forgings Gatorized ${ }^{\circledR}$ and tested at Ladish Co. Using a solution treatment of $2090^{\circ} \mathrm{F} / 2$ hours $/ 0 Q$ and an age of $1350^{\circ} \mathrm{F} / 8$ hours $/ A C$, tensile properties as a function of stabilize cycle are presented in Table V. Again, the RT ductility after the $1600^{\circ} \mathrm{F}$ stabilize dropped to slightly below goal level. All other properties exceed the goal by a substantial margin. Based on these property data and the residual stress results, a stabilize cycle of $1800^{\circ} \mathrm{F} / 1$ hour was selected.

A total of ten alternative aging cycles were examined. While there were no major effects on properties, a relatively simple cycle $\left(1350^{\circ} \mathrm{F} / 8\right.$ hours) provided a good property balance and was, therefore, selected as the final portion of the heat treatment sequence. The data are plotted in Figure 5. 


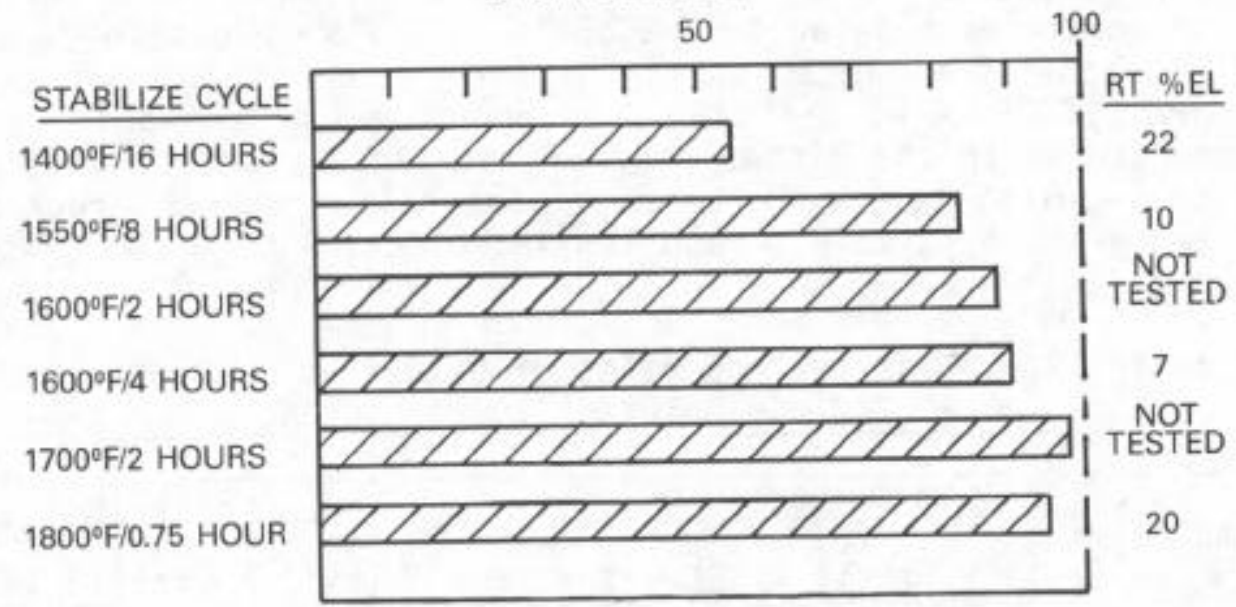

Figure 3 - Stress relief achieved with various stabilize cycles. Room temperature ductility values for selected conditions are also shown.
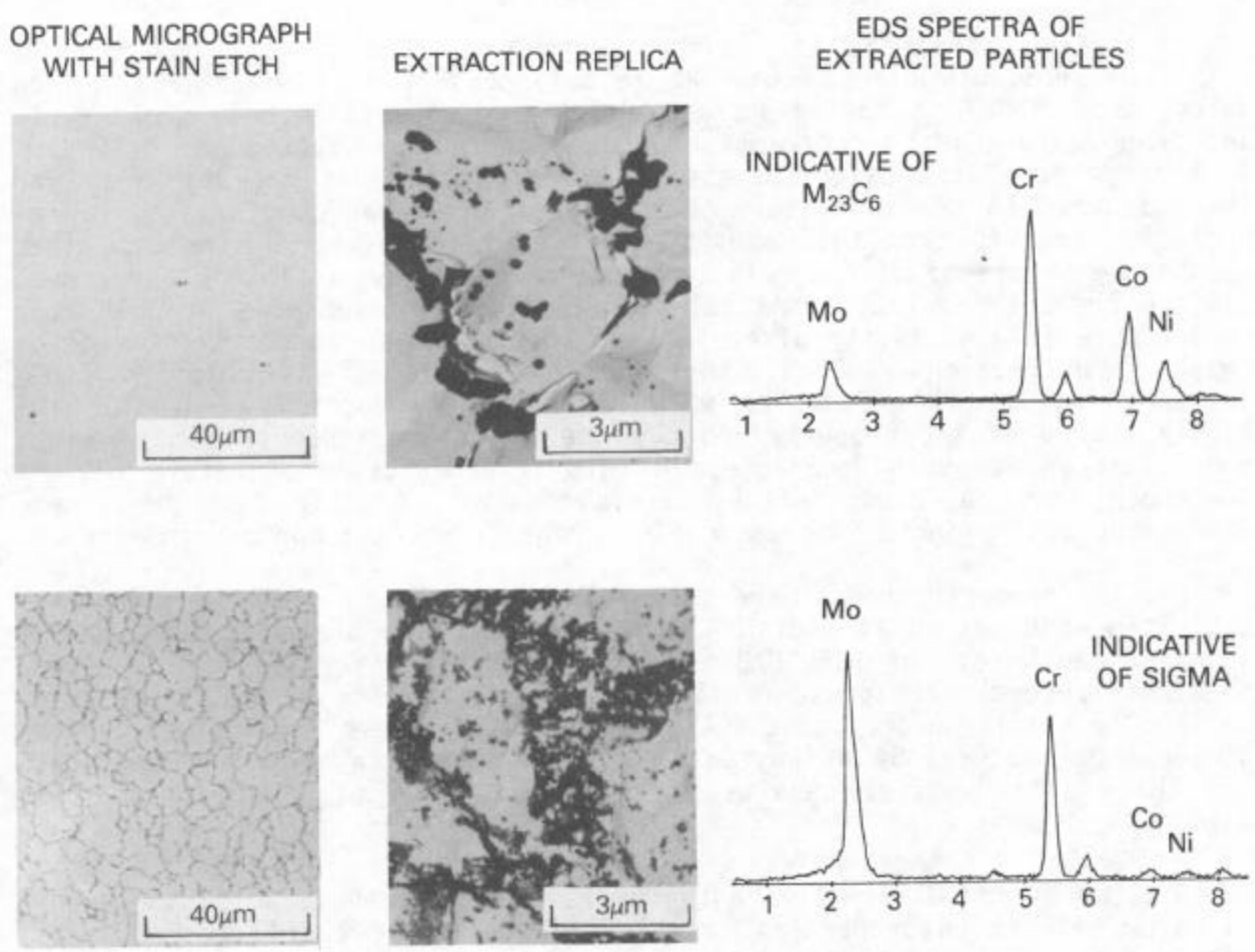

Figure 4 - Grain boundary precipitates of samples with high (top) and low (bottom) ductility. 
Table V. Tensile Properties of Gatorized® MERL 76 Versus Stabilize Cycle (Solution $=2090^{\circ} \mathrm{F} / 2$ Hours $/ 0 \mathrm{Q} ;$ Age $=1350^{\circ} \mathrm{F} / 8$ Hours $/ \mathrm{AC}$ )

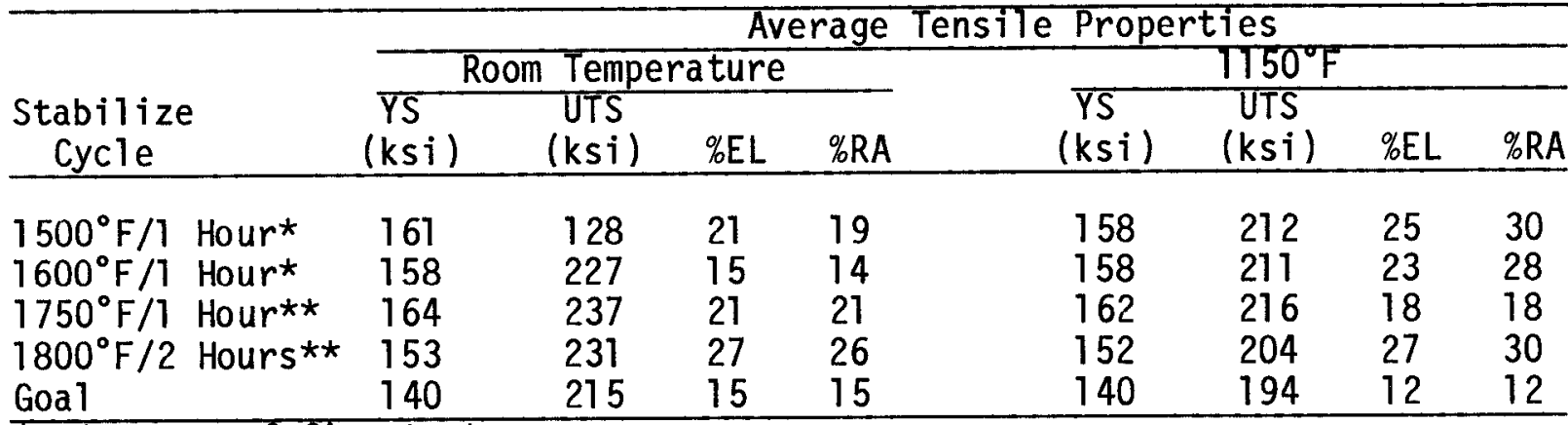

* Average of five tests

** Single test

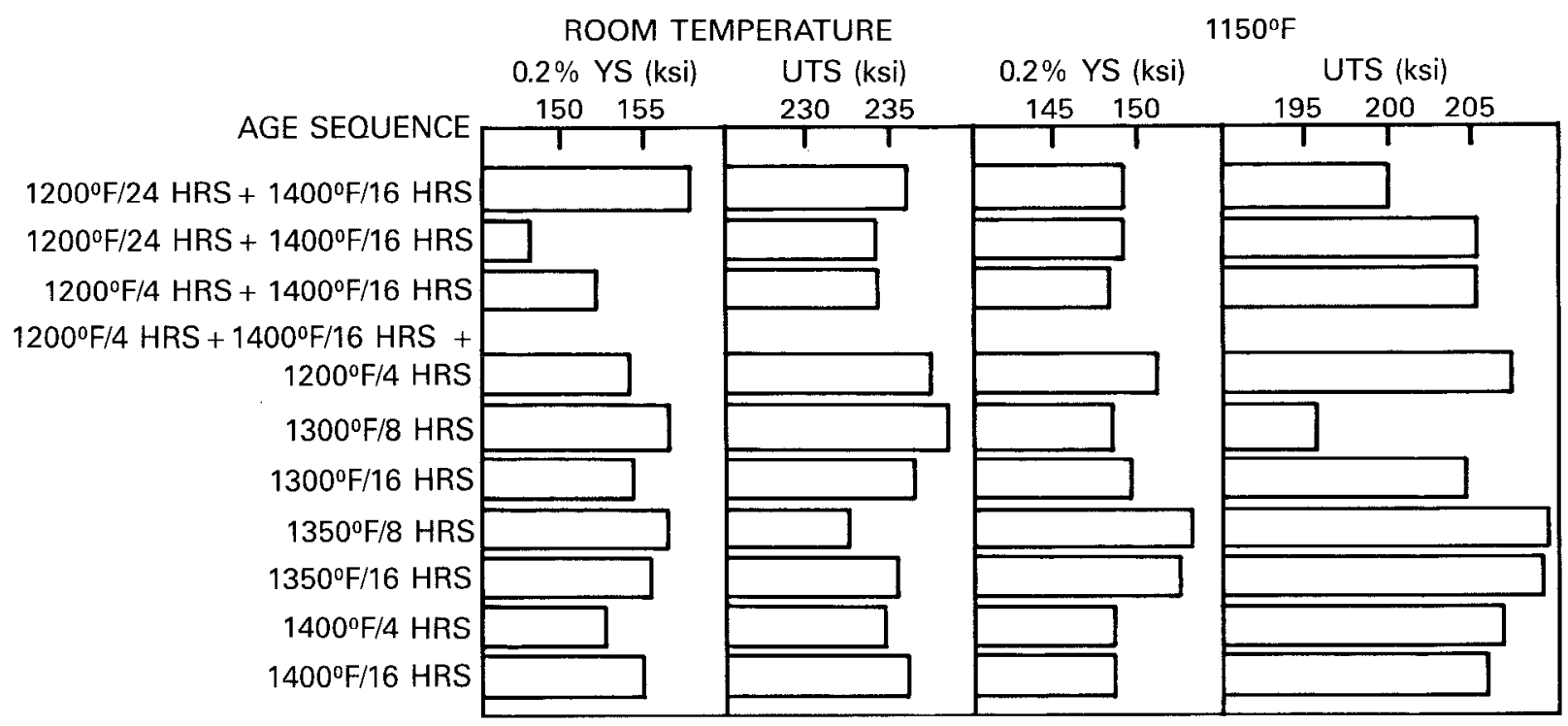

Figure 5 - Room and elevated temperature tensile properties versus age cycle.

\section{Full-Scale Process Qualification}

A comprehensive matrix of monotonic and fatigue testing was completed on full-size engine turbine disks (typical part shown in Figure 6), which were 20 to 35 inches in diameter and weighed 100 to 350 pounds. Test specimens were removed from the thickest portions of the bore, web and rim 10cations of these disks. A typical Gatorized ${ }^{\circledR}$ and heat treated MERL 76 microstructure is shown in Figure 7. This series of optical and replica micrographs reveals the three size populations of gamma prime (denoted as A, B, and $C$ in Figure 7) which result from the three heat treat steps. The coarsest size $(1$ to $4 \mu)$ is retained during the solution cycle to prevent grain coarsening. The next larger gamma prime fraction is that which grows during the $1800^{\circ} \mathrm{F}$ stabilize step (size $\left.\approx 0.2 \mu\right)$. The smallest size fraction $(<0.05 \mu$ ) is established during the $1350^{\circ} \mathrm{F}$ age. Grain size of this material, as shown in Figure 8, is ASTM 11-12. Tensile, stress-rupture, and creep properties (plotted in Figure 9) were similar to or slightly improved compared to those of the direct-HIP product form.

A large number of both smooth and notched low cycle fatigue tests were al so conducted. As shown in Figure 10, the Gatorized® product has measurably improved properties compared to HIP MERL 76. Crack growth rate capability of the two product forms was also tested and found to be similar (Figure 11). 
Since its introduction and qualification in 1983, Gatorized ${ }^{\circledR}$ MERL 76 has been specified for a variety of commercial gas turbine engine applications, most notably turbine disks, seals, and sideplates. To date, over 1000 parts have been placed in service, and performance of these has been excellent.

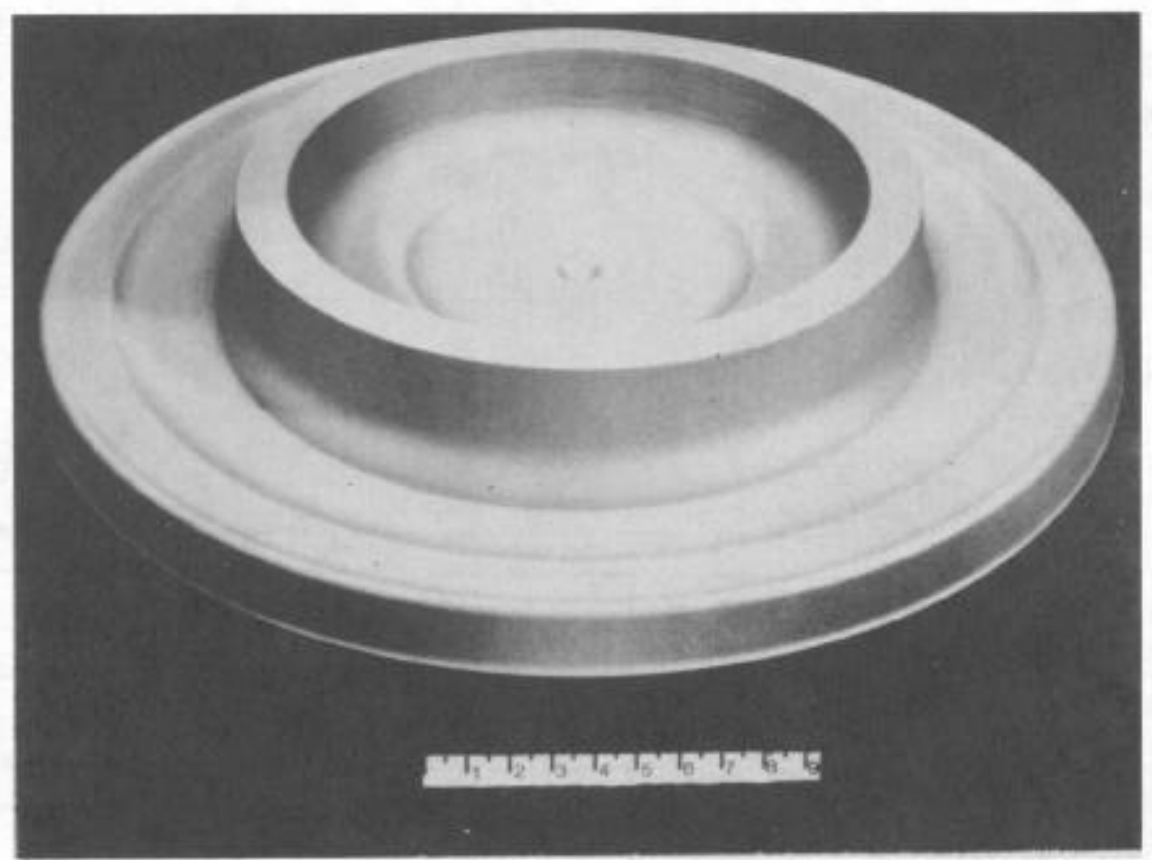

Figure 6 - Full-scale Gatorized ${ }^{(8)}$ MERL 76 forging.
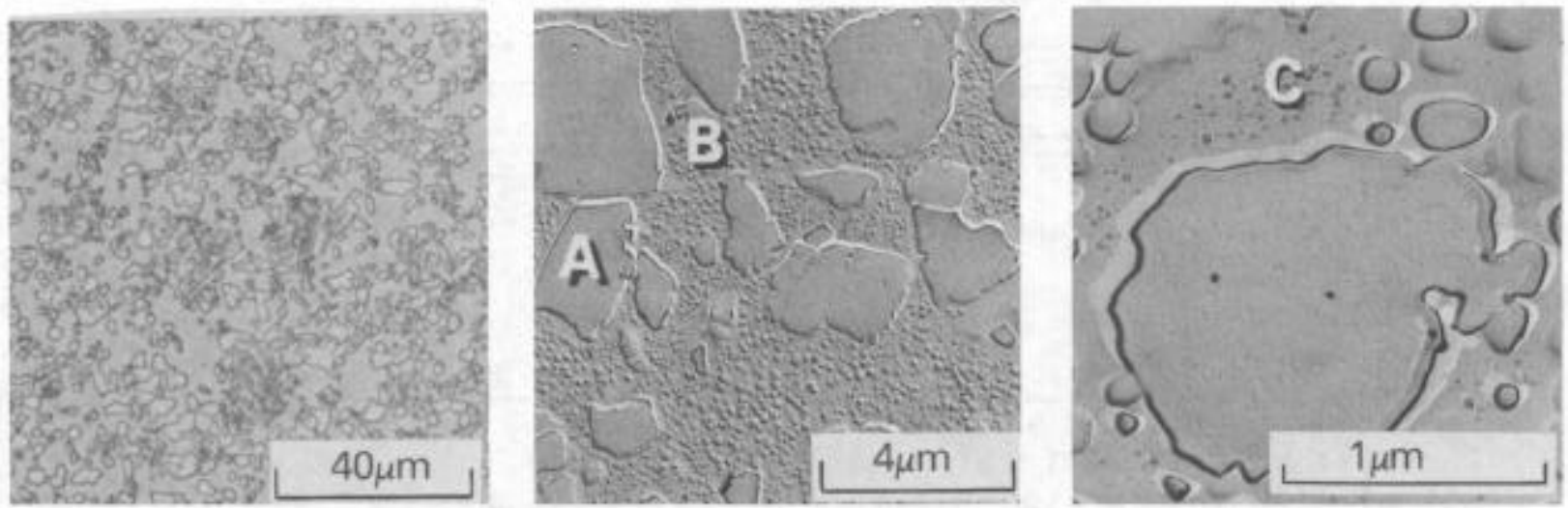

Figure 7 - Microstructure of Gatorized ${ }^{\circledR}$ and fully heat treated MERL 76 showing the three gamma prime sizes $(A, B, C)$ as described in the text.

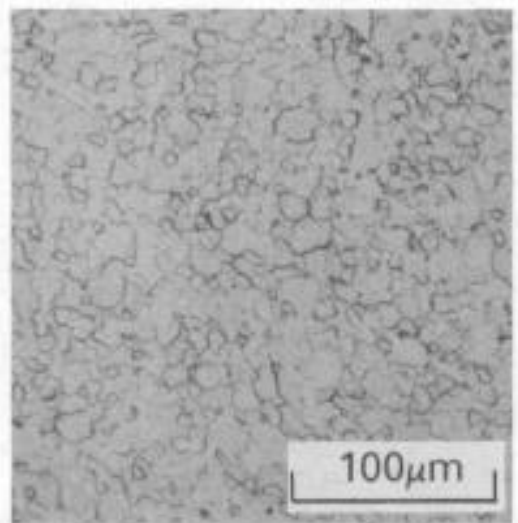

Figure 8 - Gatorized ${ }^{\circledR}$ MERL 76 saniple etched to show grain structure. Grain size: ASTM 11-12. 


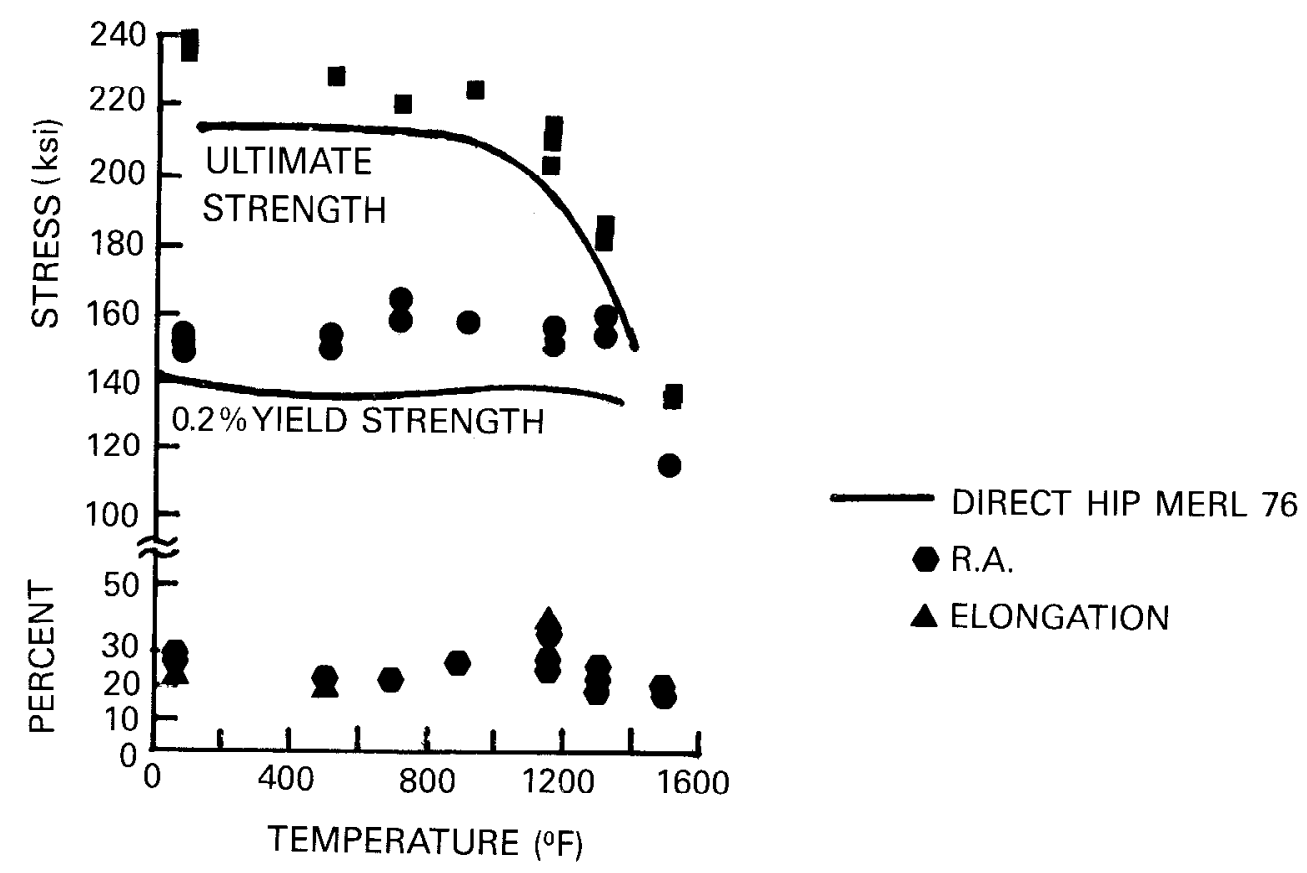

(a) TENSILE

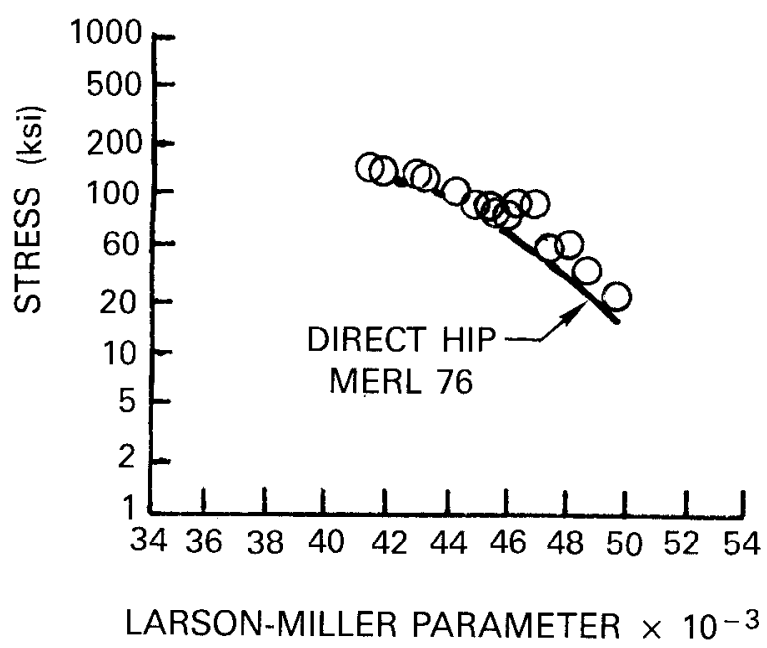

(b) STRESS-RUPTURE

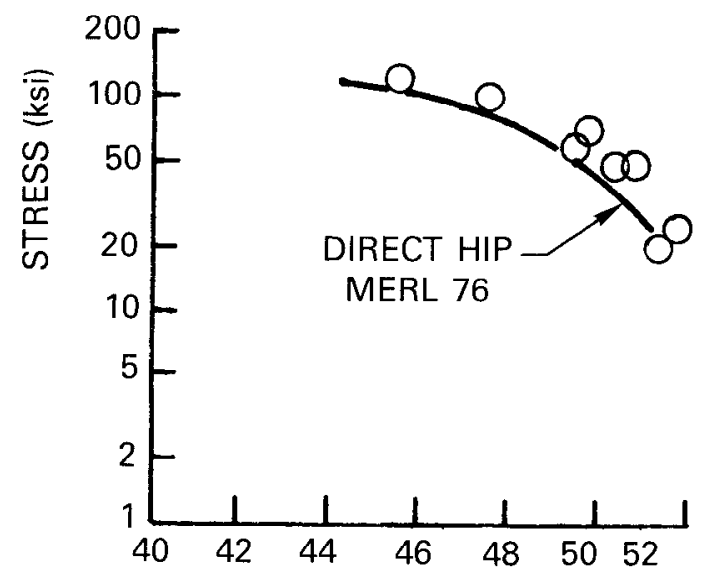

LARSON-MILLER PARAMETER $\times 10^{-3}$

(c) CREEP

Figure 9 - Monotonic properties of Gatorized ${ }^{\circledR}$ MERL 76.

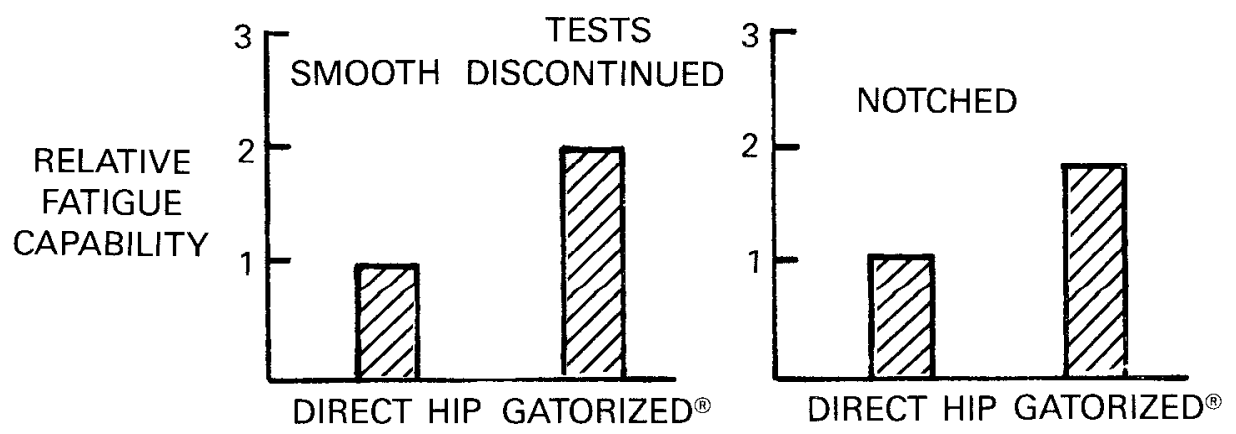

Figure 10 - Fatigue properties of Gatorized ${ }^{\circledR}$ MERL 76. 


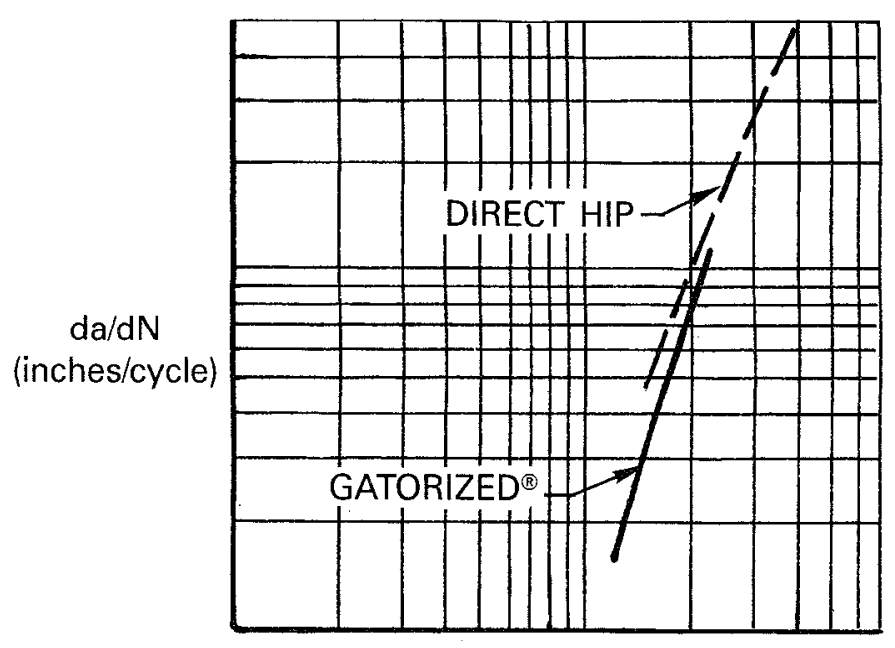

$\mathrm{K}(\mathrm{ksi}$ inch $)$

Figure 11 - Crack growth behavior of Gatorized ${ }^{\circledR}$ MERL 76.

\section{References}

1. M. J. Blackburn and R. A. Sprague, "Production of Components by Hot Isostatic Pressing of Nickel-Base Superalloy Powders," Metals Technology, (August 1977), 388-395.

2. D. J. Evans and R. D. Eng, "Development of a High Strength Hot Isostatically Pressed (HIP) Disk Alloy, MERL 76," Modern Developments in Powder Metallurgy, 14 (1981), 51-63.

3. D. R. Malley, J. E. Stulga and R. J. Ondercin, "Production of Near Net Shapes by Hot Isostatic Pressing of Superalloy Powder," 1982 National Powder Metallurgy Conference Proceedings, 38(1983), 229-246.

\section{Acknowledgements}

The authors wish to thank A. L. D'Orvilliers, R. D. Eng (formerly with Pratt \& Whitney), P. D. Genereux and A. J. Nytch for their help in conducting the experimental work; M. W. Fox for his assistance in preparing the technical illustrations; and M. J. Blackburn for his consultation and continuing support. 